\title{
Janus and Ternary Particles Generated by Microfluidic Synthesis: Design, Synthesis and Self-Assembly
}

\author{
Zhihong Nie, Wei Li, Minseok Seo,Shengqing Xu, Eugenia Kumacheva* \\ Department of Chemistry, University of Toronto, 80 St. George Street, Toronto, Ontario M5S \\ 3H6, Canada

\section{Supplemental Material}

Fabrication of Polyurethane mold Photolithographic masters were prepared with features of SU-8 (photoresist MicroChem, USA) in bas-relief on silicon wafers. Microfluidic flow-focusing devices were fabricated in polyurethane (PU) elastomer using a standard photolithographic procedure. ${ }^{1}$ Polyurethane elastomer was prepared by mixing a polyurethane intermediate (Airthane PET-60D, Air Products, USA) with 20 wt \% of poly(ethylene glycol) (Sigma-Aldrich, USA) and 0.02 wt \% of DABCO T-12 catalyst (Air Products, USA).

Geometry of microfluidic devices. Figure SI1 shows the design of the microfluidic flow-focusing device (MFFD) used in the present work. All liquids were supplied to the microchannels via polyethylene tubing (Intramedic, USA, PE60, I.D. $0.76 \mathrm{~mm}$, O.D. $1.22 \mathrm{~mm}$ ) attached to syringes operated by independent digitallycontrolled syringe pumps (Harvard Apparatus, USA, PHD 2000 series).

The MFFD was followed by the extension wavy channel (length $200 \mathrm{~mm}$, width $150 \mu \mathrm{m}$, height $120 \mu \mathrm{m}$ ) which was exposed to UV irradiation for photopolymerization of monomers. 
(a)

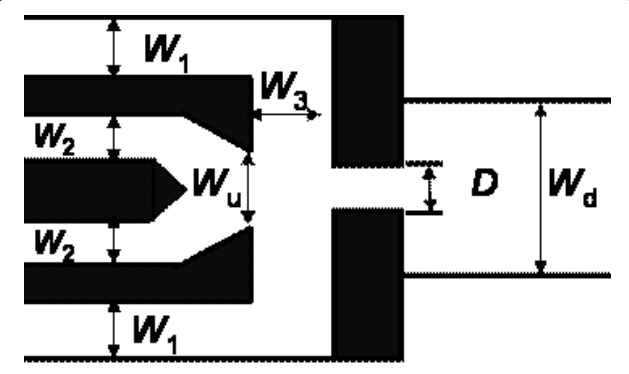

(b)

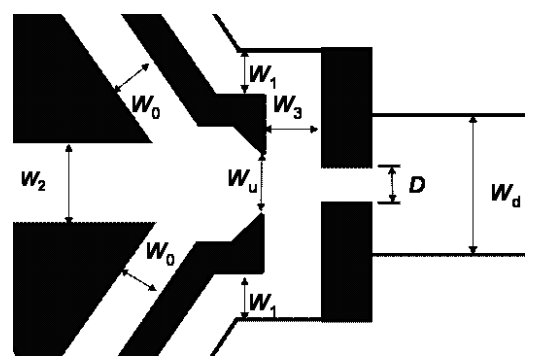

Figure S1. (a) Schematic of the MFFD used for the generation of (a) Janus droplets; (b) ternary particles. In (a) $\mathrm{W}_{\mathrm{d}}=210 \mu \mathrm{m}, \mathrm{D}=60 \mu \mathrm{m}, \mathrm{W}_{1}=150 \mu \mathrm{m}, \mathrm{W}_{2}=75 \mu \mathrm{m}, \mathrm{W}_{\mathrm{u}}=90$ $\mu \mathrm{m}$. In (b) $\mathrm{W}_{\mathrm{d}}=640 \mu \mathrm{m}, \mathrm{D}=60 \mu \mathrm{m}, \mathrm{W}_{1}=140 \mu \mathrm{m}, \mathrm{W}_{2}=80 \mu \mathrm{m}, \mathrm{W}_{0}=80 \mu \mathrm{m}, \mathrm{W}_{\mathrm{u}}=160 \mu \mathrm{m}$. In both cases the height of MFFD was $120 \mu \mathrm{m}$.

Compositions and properties of liquids. Monomer mixture M1 contained methacryloxypropyl dimethylsiloxane R11 (DMS-R11) and methacryloxypropyl dimethylsiloxane R-18 (DMS-R18), both purchased in Gelest, USA, and a photoinitiator 1-hydroxycyclohexyl phenyl ketone (HCPK). Mixture M2 contained pentaerythritol triacrylate (PETA-3); poly(ethyleneglycole) diacrylate (PEGDA); acrylic acid (AA) and HCPK (all purchased from Aldrich Canada). Liquid W was an aqueous solution of sodium dodecylsulphate (SDS). Table 1 shows the compositions and some of the properties of liquids used in the present work.

Table 1. Compositions and properties of liquids

\begin{tabular}{|c|c|c|c|c|c|}
\hline & Components & $\begin{array}{c}\text { Density } \\
\left(\mathrm{g} / \mathrm{cm}^{3}\right)\end{array}$ & $\begin{array}{c}\text { Viscosity } \\
\eta(\mathrm{cP})\end{array}$ & $\begin{array}{c}\text { Interfacial tension } \\
\gamma(\mathrm{mN} / \mathrm{m})\end{array}$ & $\begin{array}{c}\text { Spreading } \\
\text { coefficient, } \\
\mathrm{S}_{\mathrm{i}}(\mathrm{mN} / \mathrm{m}) * *\end{array}$ \\
\hline $\mathbf{M 1}$ & $\begin{array}{c}47.5 \mathrm{wt} \% \text { DMS-R11, 47.5 wt\% } \\
\text { DMS-R18 and 5.0 wt\% HCPK }\end{array}$ & 0.97 & 24.2 & $\begin{array}{c}\sigma_{\mathrm{M} 1 \mathrm{M} 2}=1.14 \\
\sigma_{\mathrm{M} 1 \mathrm{~W}}=4.89\end{array}$ & $\mathrm{~S}_{\mathrm{M} 1=-3.66}$ \\
\hline M2 & $45.0 \mathrm{wt} \%$ PETA-3, 45.0 wt\% & 1.13 & 31.1 & $\begin{array}{c}\sigma_{\mathrm{M} 1 \mathrm{M} 2}=1.14, \\
\sigma_{\mathrm{M} 2 \mathrm{~W}}=2.37\end{array}$ & $\mathrm{~S}_{\mathrm{M} 2}=1.38$ \\
& PEGDA, 5.0 wt\% AA and 5.0\% & & & - & $\mathrm{S}_{\mathrm{W}=-6.12}$ \\
\hline W & $2 \mathrm{wt} \%$ SDS aqueous solution & 1.0 & 0.998 & - & \\
\hline
\end{tabular}

* Spreading coefficients were calculated as $\mathrm{S}_{\mathrm{M} 1}=\sigma_{\mathrm{M} 2 \mathrm{~W}-}\left(\sigma_{\mathrm{M} 1 \mathrm{M} 2}+\sigma_{\mathrm{M} 1 \mathrm{~W}}\right) ; \mathrm{S}_{\mathrm{M} 2}=$ $\sigma_{\mathrm{M} 1 \mathrm{~W}}-\left(\sigma_{\mathrm{M} 1 \mathrm{M} 2}+\sigma_{\mathrm{M} 2 \mathrm{~W}}\right) ; S_{\mathrm{W}}=\sigma_{\mathrm{M} 2 \mathrm{M} 1}-\left(\sigma_{\mathrm{M} 1 \mathrm{~W}}+\sigma_{\mathrm{M} 2 \mathrm{~W}}\right)$;

\section{Photopolymerization of Janus droplets and ternary droplets.}

Photopolymerization of monomer droplets was carried out immediately after the 
release of droplets, as well as in the extension wavy channel of the microfluidics reactor. We used a UV-lamp (UVAPRINT 40C/CE, Dr. K. Hönle GmbH UV-Technologie, Germany) in the wavelength range from 330 to $380 \mathrm{~nm}$ and intensity at sample location of $200 \mathrm{~mW} / \mathrm{cm}^{2}$. The distance between the lamp and the microfluidic chip was $15-20 \mathrm{~cm}$. Typically, the time between the release of droplets and the beginning of polymerization was from 1.5 to $40 \mathrm{~ms}$ and the exposure time of droplets to UV-irradiation in the wavy channel was from 2 to $50 \mathrm{~s}$. Sometimes additional post-UV-exposure was carried out outside the microfluidics device for the further solidification particle solidification.

\section{References}

1. McDonald, J. C.; Whitesides, G. M. Acc. Chem. Res. 2002, 35, 491-499. 